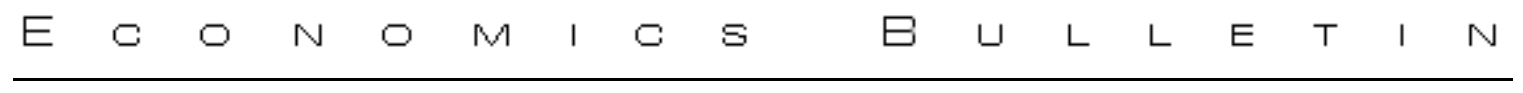

\title{
The Impact of Increasing Stock Market Integration on Expected Gains from International Portfolio Diversification: Evidence from a Multivariate Approach with Time Varying Risk.
}

\author{
AROURI Mohamed El Hedi \\ MODEM-CNRS University of Paris $X$
}

\begin{abstract}
This paper tests a conditional International Asset Pricing Model (ICAPM) using an asymmetric multivariate GARCH specification and investigates evolutions of ex ante benefits from world market diversification. The model is estimated simultaneously for 8 markets: the world market, 4 developed markets and 3 emerging markets. This approach allows to the price of market risk, betas and correlations to vary through time. The evidence supports the financial integration hypothesis and suggests that investors from all countries could expect statistically significant benefits from international diversification but that gains are considerably larger for investors with smaller home markets
\end{abstract}

I am grateful to G. PRAT and C. HARVEY for their helpful comments and suggestions.

Citation: Mohamed El Hedi, AROURI, (2004) "The Impact of Increasing Stock Market Integration on Expected Gains from International Portfolio Diversification: Evidence from a Multivariate Approach with Time Varying Risk.." Economics Bulletin, Vol. 6, No. 3 pp. 1-13

Submitted: December 22, 2003. Accepted: March 18, 2004.

URL: http://www.economicsbulletin.com/2004/volume6/EB-03F30007A.pdf 


\section{Introduction}

International diversification is often considered as the best instrument to improve portfolio performance. In fact, correlations between asset returns from different markets are lower than correlations within the same market. ${ }^{1}$ However, recently financial markets have become more integrated in response to the reduction of many restrictions and barriers. ${ }^{2}$ This increasing integration of international financial markets may have two consequences. First, the lifting of legal barriers, the reduction of information and transaction costs, the technological and financial innovations may have improved the market efficiency and increased the expected gains from international portfolio diversification. Second, financial integration may have increased cross-country correlations in recent years, which may have decreased the benefits of diversification. The global effect of stock market integration on expected gains from international portfolio diversification is ambiguous.

In this paper, I test a conditional International Capital Asset Pricing Model (ICAPM) using an asymmetric multivariate GARCH specification. The model is estimated over the period April 1973-April 2003 simultaneously for 8 markets. This approach allows to the price market risk, betas and correlations to vary through time. Then, I investigate how expected gains from world market diversification respond to increasing integration of international financial markets.

The rest of the paper is organised as follows. Section 2 presents the model and its implications for international diversification. Section 3 introduces the econometric methodology. Section 4 describes the data. Section 5 reports the empirical results. Concluding remarks are in section 6.

\section{The Conditional ICAPM and its Implications for International Diversification}

The Capital Asset Pricing Model (CAPM), originally proposed by Sharpe (1964) and Lintner (1965), predicts that the expected excess return on an asset is proportional to its nondiversifiable risk measured by its covariance with the market portfolio. Under the hypothesis of stock market integration, an international conditional version of the CAPM can be written:

$$
E\left(\tilde{R}_{i t} / \Omega_{t-1}\right)-R_{f t}=\delta_{t-1} \operatorname{Cov}\left(\tilde{R}_{i t}, \tilde{R}_{W t} / \Omega_{t-1}\right) ; \forall i
$$

where $\widetilde{R}_{i t}$ is the return on asset $\mathrm{i}$ between time $\mathrm{t} 1$ and $\mathrm{t} ; R_{f t}$ is the return on a risk-free asset; $\tilde{R}_{W t}$ is the return on the market portfolio and $\delta_{t-1} \equiv\left(E\left(\tilde{R}_{W t} / \Omega_{t-1}\right)-R_{f t}\right) / \operatorname{Var}\left(\tilde{R}_{W t} / \Omega_{t-1}\right)$ is the price of covariance risk. ${ }^{3}$ All expectations are taken with respect to the market-wide set of information $\Omega_{t-1} \cdot{ }^{4}$

Next, turn to implications of the ICAPM for international portfolio diversification. I first construct a measure of the expected benefits from international diversification, and then focus on its evolution over time.

\footnotetext{
${ }^{1}$ See for example Solnik (1974) and Roll (1992).

${ }^{2}$ See, among others, Bekaert and Harvey (1995) and Ayuso and Blanco (2000).

${ }^{3}$ Because equation (1) has to hold for the market portfolio, $\delta_{t-1}$ can be interpreted as the price of market risk.

4 This model could be considered as a special case of the international asset pricing model of Adler and Dumas (1983) in which currency risk is not significantly priced. The same model is often used in international framework (see, among others, Harvey (1991), Bekaert and Harvey (1995), De Santis and Gérard (1997), Nilsson (2002) and Gérard et al. (2003). For models with currency risk see, among others, De Santis and Gérard (1998), Carrieri (2001) and De Santis et al. (2003).
} 
To investigate this issue, consider two portfolios presenting the same time-varying risk, one internationally diversified, $P$, and one purely domestic, $p$. Hence, the time-varying expected gains from international diversification are given by the difference in expected returns on the two portfolios computed according to the ICAPM. Formally, let $\tilde{R}_{p t}$ be the return on the domestic portfolio $p$ and $\tilde{R}_{P t}=\psi_{t-1} \tilde{R}_{w t}+\left(1-\psi_{t-1}\right) \tilde{R}_{f t}$ the return on the internationally efficiently diversified portfolio $P^{5} .^{5}$ According to equation (1), the expected gains from international portfolio diversification are given by:

$$
E\left(\tilde{R}_{P t}-\tilde{R}_{p t} / \Omega_{t-1}\right)=\delta_{t-1}\left[\psi_{t-1} \operatorname{Var}\left(\tilde{R}_{W t} / \Omega_{t-1}\right)-\operatorname{Cov}\left(\tilde{R}_{p t}, \tilde{R}_{W t} / \Omega_{t-1}\right)\right]
$$

where $\psi_{t-1}^{2}=\operatorname{Var}\left(\tilde{R}_{i t} / \Omega_{t-1}\right) / \operatorname{Var}\left(\tilde{R}_{W t} / \Omega_{t-1}\right){ }^{6}$

Equation (2) suggests that the expected gains from international portfolio diversification are decreasing in the level of correlation with the market portfolio. On the other hand, expected benefits are increasing in the price of market risk and in the amount of nonsystematic risk for which investors are not remunerated. ${ }^{7}$

\section{Econometric Methodology}

Equation (1) has to hold for every asset including the market portfolio. A benchmark system of equations can be used to test the conditional ICAPM. For an economy with $N$ risky assets, the following system of pricing restrictions has to be satisfied at each point in time

$$
\tilde{R}_{t}-R_{f t} \tau=\delta_{t-1} h_{N t}+\tilde{\varepsilon}_{t} \quad \tilde{\varepsilon}_{t} / \Omega_{t-1} \sim \mathrm{N}\left(0, \mathrm{H}_{\mathrm{t}}\right)
$$

where $\tilde{R}_{t}$ denotes the $(N \times 1)$ vector that includes $(N-1)$ risky assets and the market portfolio, $\tau$ an $\mathrm{N}$-dimensional vector of ones. $\mathrm{H}_{t}$ is the $(N \times N)$ conditional covariance matrix of asset returns and $h_{t}$ is the $N^{\text {th }}$ column of $\mathrm{H}_{t}$ composed of the conditional covariance of each asset with the market portfolio.

The dynamics of conditional moments are left unspecified by the model. However, it has been shown that securities exhibit volatility clustering and leptokurtosis. Such characteristics are taken into account by ARCH specification. To estimate the model, I utilize the multivariate parsimonious GARCH process that was originally proposed by Ding and Engle (1994) and then generalized by De Santis and Gérard (1997) to accommodate the GARCH-in-mean feature typical for most tests of asset pricing models. Formally, $H_{t}$ can be written as follows: ${ }^{8}$

\footnotetext{
${ }^{5}$ See Black (1972) for the two-fund separation theorem.

${ }^{6}$ The two portfolios have the same level of conditional volatility: $\operatorname{Var}\left(\tilde{R}_{p t} / \Omega_{t-1}\right)=\operatorname{Var}\left(\tilde{R}_{P t} / \Omega_{t-1}\right)=\mathbf{\Psi}_{t-1}^{2} \operatorname{Var}\left(\tilde{R}_{W t} / \Omega_{t-1}\right)$ but different time-varying expected returns: $E\left(\tilde{R}_{p t} / \Omega_{t-1}\right)-R_{f t}=\delta_{t-1} \operatorname{Cov}\left(\tilde{R}_{p t}, \tilde{R}_{W t} / \Omega_{t-1}\right) \quad$ and $E\left(\tilde{R}_{P t} / \Omega_{t-1}\right)-R_{f t}=\delta_{t-1} \operatorname{Cov}\left(\Psi_{t-1} \tilde{R}_{W t}, \tilde{R}_{W t} / \Omega_{t-1}\right)=\delta_{t-1} \Psi_{t-1} \operatorname{Var}\left(\tilde{R}_{W t} / \Omega_{t-1}\right)$

${ }^{7}$ This intuition is obtained from the special case $\psi=1, E\left(\tilde{R}_{P t}-\tilde{R}_{p t} / \Omega_{t-1}\right)=\delta_{t-1}\left|\operatorname{Var}\left(\tilde{R}_{p t} / \Omega_{t-1}\right)-\operatorname{Cov}\left(\tilde{R}_{p t}, \tilde{R}_{W t} / \Omega_{t-1}\right)\right|$.

${ }^{8}$ I use the popular GARCH(1,1)-M parameterisation. Most empirical studies suggest that a $\operatorname{GARCH}(1,1)$ is sufficient, see for example De Santis and Gérard (1997), Nilsson (2002), Gérard et al. (2003) and De Santis et al. (2003).
} 


$$
\mathrm{H}_{t}=C^{\prime} C+A^{\prime} \varepsilon_{t-1} \varepsilon_{t-1}^{\prime} A+B^{\prime} \mathrm{H}_{t-1} B
$$

where $\mathrm{C}$ is a $(N \times N)$ symmetric matrices and $\mathrm{A}$ and $\mathrm{B}$ are $(N \times N)$ parameter matrices. This specification is often applied in empirical works. In particular, it guarantees that the conditional variance matrix is definite and positive.

Furthermore, many studies show that conditional variances and covariances are higher during stock market downturns, see for example Glosten et al. (1993) and Kroner and $\mathrm{Ng}$ (1998). I extend the equation (4) and allow for double asymmetric effects: sign effects and absolute size effects.

$$
\mathrm{H}_{t}=C^{\prime} C+A^{\prime} \varepsilon_{t-1} \varepsilon_{t-1}^{\prime} A+B^{\prime} \mathrm{H}_{t-1} B+S^{\prime} \xi_{t-1} \xi_{t-1}^{\prime} S+T^{\prime} \eta_{t-1} \eta_{t-1}^{\prime} T
$$

where $S$ and $T$ are $(N \times N)$ matrix and

$\xi_{i t}=\varepsilon_{i t} I_{\xi_{i t}}$ where $I_{\xi_{i t}}=1$ if $\varepsilon_{i t}<0$ otherwise $I_{\xi_{i t}}=0$

$\eta_{i t}=\varepsilon_{i t} I_{\eta_{i t}}$ where $I_{\eta_{i t}}=1$ if $\left|\varepsilon_{i t}\right|>\sqrt{h_{i i t}}$ otherwise $I_{\eta_{i t}}=0$

This parameterisation implies that the conditional variance is higher after negative shocks and when the squared own lagged residual is larger than its conditional expectation.

However equation (5) is very difficult to estimate due to the large number of unknown parameters. ${ }^{9}$ That is why most studies that use multivariate GARCH processes limit the analysis to a small number of assets and/or impose several restrictions on the conditional covariance-variance matrix specification. Given that I use monthly data, I believe that the spillover in volatility may not be very strong and restrict $A, B, S$ and $T$ to be diagonal. This restriction implies that the variances in $H_{t}$ depend asymmetrically only on past squared residuals and an autoregressive component, while the covariances depend asymmetrically upon past cross-products of residuals and an autoregressive component. Finally, note that the parameterisation I adopt allows particularly for time-varying asymmetric correlation structure between countries which is potentially important when evolutions of expected gains from international portfolio diversification are investigated.

Next, turn to the price of market risk. Many previous studies use the conditional international CAPM with constant price of risk. However this assumption is often rejected by the data. ${ }^{10}$ On the other hand, empirical research has found support for a time-varying price of risk. $^{11}$ The price of risk is often modeled as a function of a certain number of instruments, which are designed to capture expectation about business cycle fluctuations. The logic, which justifies the use of these instruments, is that investors become more risk averse during economic troughs while the market price of risk decreases during expansionary phases of the business cycle. This flexibility provided by a time-varying price of risk allows the model to better accommodate periods when realized return is a bad proxy for the expected return. But assuming time-varying price of market risk does not come without costs. In fact, in some periods the estimated price of covariance risk is negative. However, as documented by Merton

\footnotetext{
9 Because I work with a cross-section of seven countries together with the world market, I have $292=N(N+1) / 2+4 N^{2}$ parameters to estimate only for the variance equation.

${ }^{10}$ For example, see Harvey (1991) and De Santis and Gérard $(1997,1998)$.

11 See for instance Harvey (1991), Bekaert and Harvey (1995), Dumas and Solnik (1995), Carrieri (2001), Gérard et al. (2003) and De Santis et al. (2003).
} 
(1980) and Adler and Dumas (1983), the price of market risk is a weighted average of the coefficients of risk aversion of all national investors; therefore, if investors are risk averse the price of market risk must always be positive. For this reason, a common literature suggests to impose the restriction: $\delta_{m, t-1}>0 .{ }^{12}$ Nevertheless, authors argued that the rejection of the conditional CAPM in some cases is a consequence of this positivity restriction. ${ }^{13}$ This restriction appears to assume the difficulty away rather than solve it. In fact, there is evidence against the theoretical model only if we believe that the expected excess return is sometimes negative in equilibrium. An estimated negative price of market risk simply reflects that the econometric model adopts to negative realized returns. Therefore, one should to be cautious to evaluate the conditional CAPM on a period by period basis and instead consider averages over long periods. ${ }^{14}$ In this article, I use a linear function of instrumental variables to model the world market price of risk:

$$
\boldsymbol{\delta}_{m, t-1}=\kappa_{m}^{\prime} Z_{t-1}
$$

where $\mathrm{Z}_{t-1}$ are global information variables that are available to the investor at $(\mathrm{t}-1)$ and $\kappa_{m}$ is a set of weights that the investor uses to evaluate the conditionally expected returns. ${ }^{15}$

Equations (3), (5) and (6) constitute our benchmark model. Under the assumption of conditional normality, the log-likelihood function can be written as follows:

$$
\ln L(\boldsymbol{\theta})=-\frac{T N}{2} \ln (2 \pi)-\frac{1}{2} \sum_{t=1}^{T} \ln \left[\operatorname{det}\left(\mathrm{H}_{t}(\boldsymbol{\theta})\right)\right]-\frac{1}{2} \sum_{t=1}^{T} \boldsymbol{\varepsilon}_{t}^{\prime}(\boldsymbol{\theta}) \mathrm{H}_{t}^{-1}(\boldsymbol{\theta}) \boldsymbol{\varepsilon}_{t}(\boldsymbol{\theta})
$$

where $\theta$ is the vector of unknown parameters. To avoid incorrect inference due to the misspecification of the conditional density of asset returns the quasi-maximum likelihood (QML) approach of Bollerslev and Wooldridge (1992) is used. Simplex algorithm is used to initialize the process, then the estimation is performed using (BHHH) algorithm developed by Berndt, Hall, Hall and Hausman (1974).

\section{Data and Preliminary Analysis}

I use monthly returns on stock indexes for seven countries plus a value weighted world market index over the period April 1973 - April 2003. All the indices are obtained from DataStream, computed in excess of the 30-day eurodollar deposit rate obtained from DataStream and expressed in the American dollar. The world market return is computed from MSCI world index available from DataStream. Given the aim of the paper, I select four developed countries (the United States, France, Great Britain and Japan) and three emerging countries (Singapore, Hong Kong and South Africa). Descriptive statistics for the eight excess returns are reported in table I.

Table I reveals a number of interesting facts. The Bera-Jarque test statistic strongly rejects the hypothesis of normally distributed returns, which supports my decision to use

\footnotetext{
${ }^{12}$ Harvey (1991), De Santis and Gérard (1997,1998), Bekaert and Harvey (1995), Carrieri (2001), Hardouvelis et al. (2002) and De Santis and Al. (2003) use an exponential function of the instruments.

${ }^{13}$ See De Santis and Gérard (1997).

14 In reality, this conclusion reflects the contents of the rational expectations hypothesis underlying the empirical formulation of the conditional CAPM; given information, expectations are correct on average, but not necessarily period by period.

${ }^{15}$ Note that $Z_{t-1}$ is a subset of the true information set $\Omega_{t-1}$.
} 
QML to estimate and test the model. The values of cross-correlations are relatively low, especially if compared to the average correlation among sectors of the US market. ${ }^{16}$ This suggests that there are still benefits from diversification across markets. The lack of autocorrelation in the return series reveals that we do not need to include an AR correction in the mean equations.

For the squared returns, autocorrelation is detected at short lags, which suggests that GARCH parameterisation for the second moments might be appropriate at least for stock returns series. Panel D contains the cross-correlations of squared returns between the world and the other countries at different leads and lags. With few exceptions, only the contemporaneous correlations are statistically significant. When we analyse the crosscorrelations with at most two leads and two lags, only 14 out of 112 are significant. This evidence suggests that, at least with our monthly data, the croos-market dependence in volatility is not strong and that the diagonal GARCH parameterisation for the second moments is not too restrictive.

Summary statistics for the conditioning information set are in table II. In order to preserve the comparability between this study and others studies, the choice of global information variables is mainly drawn from previous empirical literature in international asset pricing. The set of global information includes a constant, the three month moving average of world excess returns, the change in the US term premium spread measured by the yield on the ten-year US Treasury note in excess of the one-month T-Bill rate, the US default premium measured by the difference between Moody's Baa-rated and Aaa-rated corporate bonds, the change in the American inflation rate and the change in industrial production. All variables are used with one-month lag relative to the excess equity returns. As a check for multicollinearity, the statistics displayed in table II show that the correlations among the information variables are low. This evidence shows that our proxy of the information set contains nonredundant variables.

\section{Empirical Evidence}

Table III contains parameter estimates and a number of diagnostic tests for the conditional ICAPM. Panel A and panel B show QML estimates of the parameters for the mean and the covariance equations.

The annualized average price of market risk is equal to 0.256 and highly significant, which is consistent with the findings by earlier studies. The dynamic of the world price of market risk is driven by the three month moving average of world excess returns, the change in the term premium spread and in part by the January dummy variable. Figure 1 plots the time-varying price of risk. As in earlier studies, the point estimates are very noisy. ${ }^{17}$ Since we are interested in the trend in the series, the Hodrick and Prescott (1986) filter (HP) is used to separate the short-term components from the long term component. A simple visual inspection of the chart shows that the price of market risk reaches its highest values in the Seventies, becomes consistently negative in the early Eighties. As argud by De Santis and Gérard (1997), interest rates and inflation were, during those years, unusually high and the slope of the yield curve was often negative. Finally, the price of market risk increase again form the middle of the Eighties and decreases significantly in the last years of our sample.

\footnotetext{
16 Elton and Gruber (1992) argue that during the period 1980-1988, the correlation between a value-weighted index of the largest 1000 stocks traded in the US and a value-weighted of the next 2000 largest stocks is equal to $92 \%$.

${ }^{17}$ See for examples Harvey (1991) and De Santis and Gérard (1997,1998).
} 
The ARCH coefficients and GARCH coefficients are significant for most assets. This is on line with previous results in the literature. The coefficients $A$ measure the impact of past shocks on conditional variance. These coefficients are relatively small in size, which indicates that conditional volatility does not change very rapidly. However, the coefficients $B$, which measure the impact of lagged volatility on current volatility, are large, indicating gradual fluctuations over time.

One of the advantages of our approach is to authorize for asymmetric variance and covariance effects. The significant coefficients in the vector $S$ imply that the conditional variance is higher for negative shocks for the United States, South Africa and Japan. The significant coefficients in $S$ are all positive, which implies that conditional covariances between these countries increase after common negative shocks. In the same way, the significant coefficients in vector $T$ indicate that the conditional variance is higher after shocks large in absolute value for the U. S., Hong Kong, Singapore and the U.K. The significant coefficients in $T$ have the same sign (negative). This result shows that conditional covariances between these countries increase after large common negative or positive shocks.

Diagnostics of standardized residuals are provided in panel B of table III. ${ }^{18}$ One can remark that the indexes of kurtosis are often lower than those for the excess returns. However, the Jarque-Bera test statistics for normality indicates that the unconditional distribution of the conditionally normal GARCH process is not sufficiently fat-tailed to accommodate the excess kurtosis in the data. This result justifies the use of the QML procedures. I also compute the Ljung-Box statistic to test the null hypothesis of absence of autocorrelation. The results show that the specification GARCH $(1,1)$ I use is flexible enough to capture the dynamics of the conditional covariance matrix.

Table IV reports some specification tests. The conditional version of the model implies that investors update their strategy using the new available information. Thus, there is no reason to believe that the equilibrium price of risk will stay constant. The robust Wald test for the significance of the time-varying parameters in the price of world market risk rejects the null hypothesis at any standard level. For the model with partial market segmentation, the Wald test statistics show that neither the intercepts, nor the country specific volatilities are priced, which is consistent with the results in De Santis and Gerard (1997). Taken together, we find strong empirical support for the ICAPM. Next, turn to expected benefits from international diversification. The benchmark model is reestimate form the perspective of investors from each market using excess returns expressed in the corresponding currency.

Figures 2 to 8 plot for each market the time-varying series of expected gains from international portfolio diversification, together with conditional correlation with the world market. Table $\mathrm{V}$ shows the averages of the ex ante benefits from international diversification, computes separately for the full period April 1973- April 2003 and for the three sub-periods April 1973- March 1983, April 1983- March 1993 and April 1993- April 2003.

The results show that investors from all investigated markets could expect statistically significant gains from world market diversification. However, these benefits are clearly larger for small markets. The largest gains over the whole period are for Hong Kong and South Africa, on average $7.47 \%$ and $7.32 \%$ per year respectively. The smallest expected gains are for the U.S. and the U.K., on average $1.31 \%$ and $2.07 \%$ per year respectively. One explanation for this result is that investment opportunities are more limited for small countries

\footnotetext{
${ }^{18}$ In the multivariate framework, the joint standardized residuals are given by $\boldsymbol{\varepsilon}_{t}^{s}=H_{t}^{-1 / 2} \varepsilon_{t}$.
} 
and hence conditional correlations with the world portfolio should be lower. The inspection of graphs confirms this view.

The first sub-period 1973-1983 is characterized by relatively low ex ante gains from world market diversification. The largest benefit over this subperiod $(4.91 \%)$ is associated with the Hong Kong market and the smallest benefit $(0.93 \%)$ is associated with the U.S. During the second sub-period 1983-1993, expected benefits have increased considerably for all countries. Gains vary from $1.81 \%$ for the U.S. to $11.14 \%$ for South Africa. This sub-period is characterized by important globalisation and market liberalization movements. For the subperiod 1993-2003, the evolutions of expected gains from international portfolio diversification are hybrid. Expected gains have increased for the U.K. and Japan and decreased for the others countries.

To sum up, our findings show that there is only a slight tendency for expected gains from world portfolio diversification to decrease over time. One possible explanation for this result can be obtained from inspection of time-varying correlation graphs. Except for Singapore and the U.K., we find weak support for the view that cross-country correlations have increased during the recent decades as a result of market integration.

More interesting, the expected gains from diversification for the U.K. have increased despite the apparent increase in its correlations with the world portfolio. This evidence is in line with our a priori intuition that both correlations and the amount of specific risk in relation to world market risk should be taken into account when studying gains from international portfolio diversification.

\section{Conclusion}

In this paper, I extend the conditional ICAPM of De Santis and Gérard (1997) using an asymmetric multivariate GARCH specification. The model is estimated, for the period April 1973-April 2003, simultaneously for 8 markets: the world market, 4 developed markets and 3 emerging markets. This approach, with sign and size asymmetric effects, allows to the price of world market risk, betas and correlations to vary through time. The evidence supports the ICAPM and the financial integration hypothesis. Then, I investigate ex ante benefits from world market diversification. The evidence shows that investors from all countries could expect statistically significant benefits from international portfolio diversification but that gains are considerable larger for investors with smaller home markets. Interestingly, our findings show that there is only a slight tendency for expected gains from world portfolio diversification to decrease over time in response to changing market conditions.

\section{References}

- ADLER M. and B. DUMAS (1983), "International Portfolio Selection and Corporation Finance: A Synthesis", Journal of Finance, n 38 , pp. 925-84.

- AYUSO J. and R. BLANCO (2000), "Has Financial Integration Increased During the 1990s?", In Bis Conference Volume. International Financial Markets and Implications for Monetary and Financial Stability, pp. 75-95.

- BEKAERT T. and C. HARVEY (1995), “Time Varying World Market Integration”, Journal of Finance, 50(2), pp. 403-44.

- BERNDT G., B. HALL, R. HALL and J. HAUSMANN (1974), "Estimation and Inference in Nonlinear Structural Models", Annals of Economics and Social Measurement, 3, pp. 653-665.

- BLACK F. (1972), "Capital Market Equilibrium with Restricted Borrowing", Journal of Business, n 45,pp.444-454.

- BOLLERSLEV T., R.F. ENGLE and M. WOOLDRIDGE (1992), "A Capital Asset Pricing Model with Time Series Varying Covariance", Journal of Political Economy. 
- CARRIERI F. (2001), "The Effects of Liberalisation on Market and Currency Risk in the European Union”, European Financial Management, 7, pp. 259-290.

- DE SANTIS G. and B. GERARD (1997), "International Asset Pricing and Portfolio Diversification with Time-Varying Risk", Journal of Finance 52, 1881-1912.

- DE SANTIS G. and B. GERARD (1998), "How Gig is the Premium for Currency Risk", Journal of Financial Economics, 49, pp. 375-412.

- DE SANTIS G., B. GERARD and P. HILLION (2003),“The Relevance of Currency Risk in the EMU", Journal of Economics and Business, 55, pp. 427-462.

- DING Z. and F. ENGLE (1994), "Large Scale Conditional Covariances Matrix Modelling, Estimation and Testing", Working Paper, University of California at San Diego.

- DUMAS B. and B. SOLNIK (1995), “The World Price of Foreign Exchange Risk?”, Journal of Finance, 50, pp. 445-479.

- ELTON E and J. GRUBER (1992), "International Diversification”, in summer N. Levine, ed. Global Investing.

- GERARD B., K. THANYALAKPARK and J. BATTEN (2003), “Are the East Asian Markets Integrated? Evidence from the ICAPM", Journal of Economics and Business, 55, pp. 585-607.

- GLOSTEN L., R. JAGANNATHAN and D. RUNKLE (1993),"Relationship Between the Expected Value and the Volatility of National Excess Return on Stocks", Journal of Finance, 48, pp. 1779-1801.

- HARDOUVELIS G., P. MALLIAROPOULOS and D. PRIESTLEY (2002), "EMU and Stock Market Integration", Working Paper.

- HARVEY C. (1991), "The World Price of Covariance Risk", Journal of Finance, vol 46(1),pp. 111-57.

- HODRICK R. and E. PRESCOTT (1986),"Post-War US Business Cycles: A Descriptive Empirical Investigation", Mark Watson, Federal Reserve Bank of Chicago.

- KRONER K. and V. NG (1998),"Modelling Asymmetric Comovements of Asset Returns", Review of Financial Studies, 11, pp. 817-844.

- LINTNER J. (1965), "The Valuation of Risky Assets and the Selection of the Risky Investments in Stock Portfolios and Capital Budgets", Reviews of Economics and Statistics, 47, pp.13-37.

- MERTON R. (1980), "On estimating the Expected Return on the Market: An Explonary Investigation", Journal of Financial Economics, 8(4), pp. 323-361.

- NILSSON B. (2002), "International Asset Pricing and the Benefits from World Market Diversification", Department of Economics, Lind University, February 1, 2002.

- PRAT G. (1982), "La Bourse et la Conjoncture Economique”, Economica.

- ROLL R. (1992), "Industrial Structure and the Comparative Behaviour of International Stock Market Indices", Journal of Finance 47, pp. 3-42.

- SHARPE W. (1964), "Capital Asset Prices: A Theory of Market Equilibrium under Conditions of Risk", Journal of Finance, ${ }^{\circ}$ 9, pp.725-742.

- SOLNIK B (1974), "An Equilibrium Model of International Capital Market", Journal of Economic Theory, 8, pp.91-135.

\section{Table I: Descriptive statistics of asset excess returns}

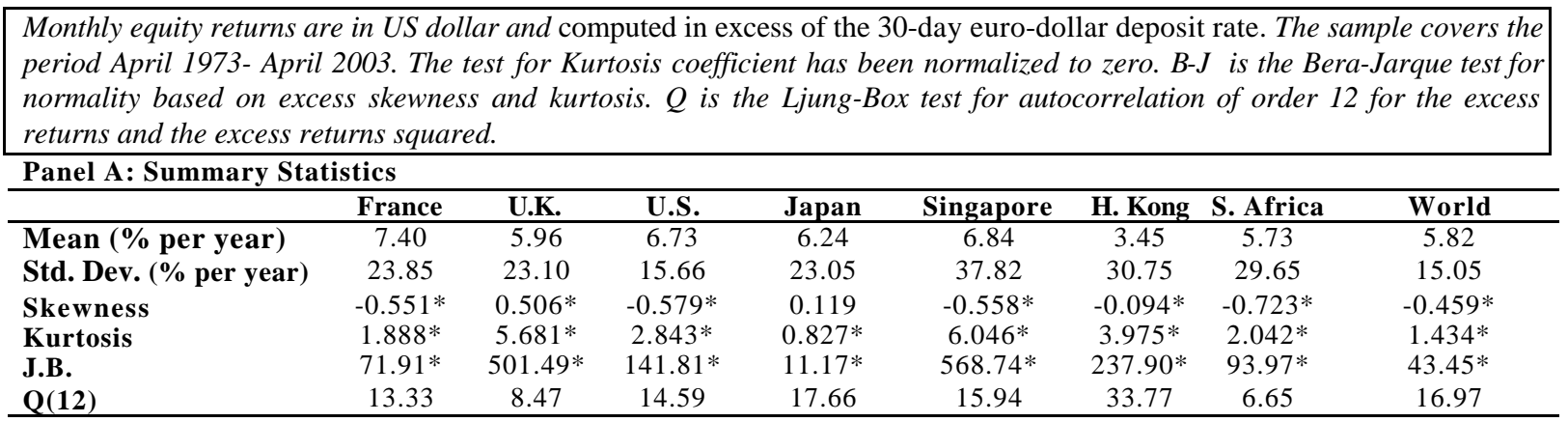


Table I-Continued

Panel B: Unconditional correlations of $r_{i t}$

\begin{tabular}{|c|c|c|c|c|c|c|c|c|c|}
\hline & France & U.K. & U.S. & \multicolumn{2}{|c|}{ Japan } & Singapore & H. Kong & S. Africa & World \\
\hline France & 1.00 & 0.56 & 0.51 & & 40 & 0.33 & 0.31 & 0.42 & 0.67 \\
\hline U.K. & & 1.00 & 0.56 & & 37 & 0.52 & 0.41 & 0.32 & 0.71 \\
\hline U.S. & & & 1.00 & & 30 & 0.54 & 0.41 & 0.34 & 0.83 \\
\hline Japan & & & & & 00 & 0.33 & 0.29 & 0.31 & 0.66 \\
\hline Singapore & & & & & & 1.00 & 0.60 & 0.28 & 0.59 \\
\hline H. Kong & & & & & & & 1.00 & 0.27 & 0.49 \\
\hline S. Africa & & & & & & & & 1.00 & 0.46 \\
\hline World & & & & & & & & & 1.00 \\
\hline \multicolumn{10}{|c|}{ Panel C: Autocorrelation of $\left(r_{i t}\right)^{2}$} \\
\hline & $\rho_{1}$ & $\rho_{2}$ & $\rho_{3}$ & $\rho_{4}$ & $\rho_{5}$ & $\rho_{6}$ & $\rho_{12}$ & $\mathrm{Q}(12)$ & Prob. \\
\hline France & 0.05 & 0.03 & 0.02 & 0.10 & -0.01 & -0.01 & -0.05 & 16.11 & 0.18 \\
\hline U.K. & $0.18 *$ & 0.17 & 0.09 & $0.07 * * *$ & 0.20 & 0.2 & 0.01 & $50.09 * *$ & 0.01 \\
\hline U.S. & 0.14 & 0.10 & 0.10 & 0.05 & 0.00 & 0.03 & 0.02 & 25.15 & 0.13 \\
\hline Japan & $0.13 *$ & $0.07 * *$ & -0.01 & -0.01 & 0.12 & 0.09 & -0.01 & $32.67 * *$ & 0.06 \\
\hline Singapore & $0.17 *$ & 0.06 & $0.12 * *$ & 0.10 & 0.08 & 0.13 & 0.14 & $47.80 * *$ & 0.02 \\
\hline H. Kong & $0.13 *$ & $0.18 *$ & 0.09 & 0.07 & $0.02 * *$ & 0.06 & 0.09 & $31.14 * *$ & 0.08 \\
\hline S. Africa & $0.22 *$ & $0.27 *$ & 0.06 & 0.03 & 0.06 & -0.01 & 0.03 & $32.55 * *$ & 0.02 \\
\hline World & 0.05 & -0.04 & 0.04 & -0.02 & 0.08 & -0.03 & 0.08 & 16.97 & 0.15 \\
\hline \multicolumn{10}{|c|}{ Panel D: Cross-correlations of $\left(r_{i t}\right)^{2}-$ World and Country $\mathbf{j}$} \\
\hline Lag & \multicolumn{2}{|c|}{ France } & U.k. & \multicolumn{2}{|c|}{ U.S. } & Japan & Singapore & H. Kong & S. Africa \\
\hline-6 & \multicolumn{2}{|l|}{0.01} & 0.00 & \multicolumn{2}{|c|}{-0.01} & -0.04 & 0.02 & 0.08 & 0.01 \\
\hline-5 & 0.05 & & -0.07 & \multicolumn{2}{|c|}{0.06} & 0.06 & -0.03 & -0.00 & 0.00 \\
\hline-4 & -0.01 & & -0.01 & \multicolumn{2}{|c|}{-0.00} & 0.04 & 0.02 & -0.04 & -0.02 \\
\hline-3 & $0.11 *$ & & 0.06 & \multicolumn{2}{|c|}{0.02} & 0.04 & 0.02 & -0.01 & 0.05 \\
\hline-2 & -0.00 & & -0.02 & \multicolumn{2}{|c|}{-0.02} & -0.01 & -0.03 & 0.00 & -0.00 \\
\hline-1 & 0.01 & & 0.03 & \multicolumn{2}{|c|}{0.01} & 0.07 & 0.07 & -0.00 & 0.06 \\
\hline $\mathbf{0}$ & $0.67 *$ & & $0.71 *$ & \multicolumn{2}{|c|}{$0.83 *$} & $0.66 *$ & $0.59 *$ & $0.50 *$ & $0.46 *$ \\
\hline 1 & 0.06 & & 0.03 & 0.09 & & 0.06 & 0.06 & 0.03 & 0.01 \\
\hline 2 & -0.03 & & -0.03 & -0.0 & & -0.00 & -0.03 & 0.03 & -0.01 \\
\hline 3 & 0.08 & & 0.02 & 0.05 & & 0.00 & -0.04 & 0.00 & 0.04 \\
\hline 4 & 0.03 & & 0.00 & -0.0 & & -0.03 & 0.00 & 0.01 & -0.04 \\
\hline 5 & 0.03 & & 0.05 & 0.06 & & 0.05 & 0.00 & 0.02 & -0.08 \\
\hline 6 & -0.05 & & -0.03 & -0.0 & & 0.00 & -0.06 & -0.01 & -0.03 \\
\hline & & Numbe & gnifica & C & . & $\operatorname{order}(-2$, & ,2): $14 \mathrm{ou}$ & & \\
\hline
\end{tabular}

Table II: Descriptive statistics for information variables

The global information set includes a constant, the three month moving average of world excess returns (MMSCI), the change in the US term premium spread (DUSTP), the US default premium (USDP), the change in the American inflation rate (DINF) and the change in industrial production (DIP). The sample covers the period April 1973-April 2003. The test for Kurtosis coefficient has been normalized to zero. B-J is the Bera-Jarque test for normality. $Q$ is the Ljung-Box test for autocorrelation of order 12.

\begin{tabular}{|c|c|c|c|c|c|}
\hline \multicolumn{6}{|c|}{ Panel A: Summary Statistics } \\
\hline & MMSCI & DUSTP & USDP & DINF & DIP \\
\hline Mean (\% per year) & 5.88 & 0.81 & 1.10 & 0.40 & 0.18 \\
\hline Std. Dev. (\% per year) & 8.83 & 0.51 & 0.46 & 0.32 & 0.23 \\
\hline Skewness & $-0.43 *$ & $-1.00 *$ & $1.11 *$ & $0.92 *$ & $-0.07 *$ \\
\hline Kurtosis & $0.92 *$ & $0.96 *$ & $1.03 *$ & $1.24 *$ & 8.14 \\
\hline J.B. & $24.25 *$ & $74.31 *$ & $91.53^{*}$ & $74.75^{*}$ & $998.93^{*}$ \\
\hline$Q(12)$ & 259.92 & 2095.94 & 2336.62 & 1361.75 & 303.26 \\
\hline \multicolumn{6}{|c|}{ Panel B: Unconditional correlations } \\
\hline \multicolumn{2}{|c|}{\begin{tabular}{|c|} 
MMSCI \\
\end{tabular}} & DUSTP & USDP & DINF & DIP \\
\hline MMSCI & & 0.19 & 0.16 & -0.19 & -0.09 \\
\hline DUSTP & & 1.00 & -0.01 & -0.56 & 0.07 \\
\hline USDP & & & 1.00 & 0.14 & -0.07 \\
\hline DINF & & & & 1.00 & 0.03 \\
\hline DIP & & & & & 1.00 \\
\hline
\end{tabular}


Table III: Quasi-maximum likelihood estimates of the conditional International CAPM with time- varying world market price of risk

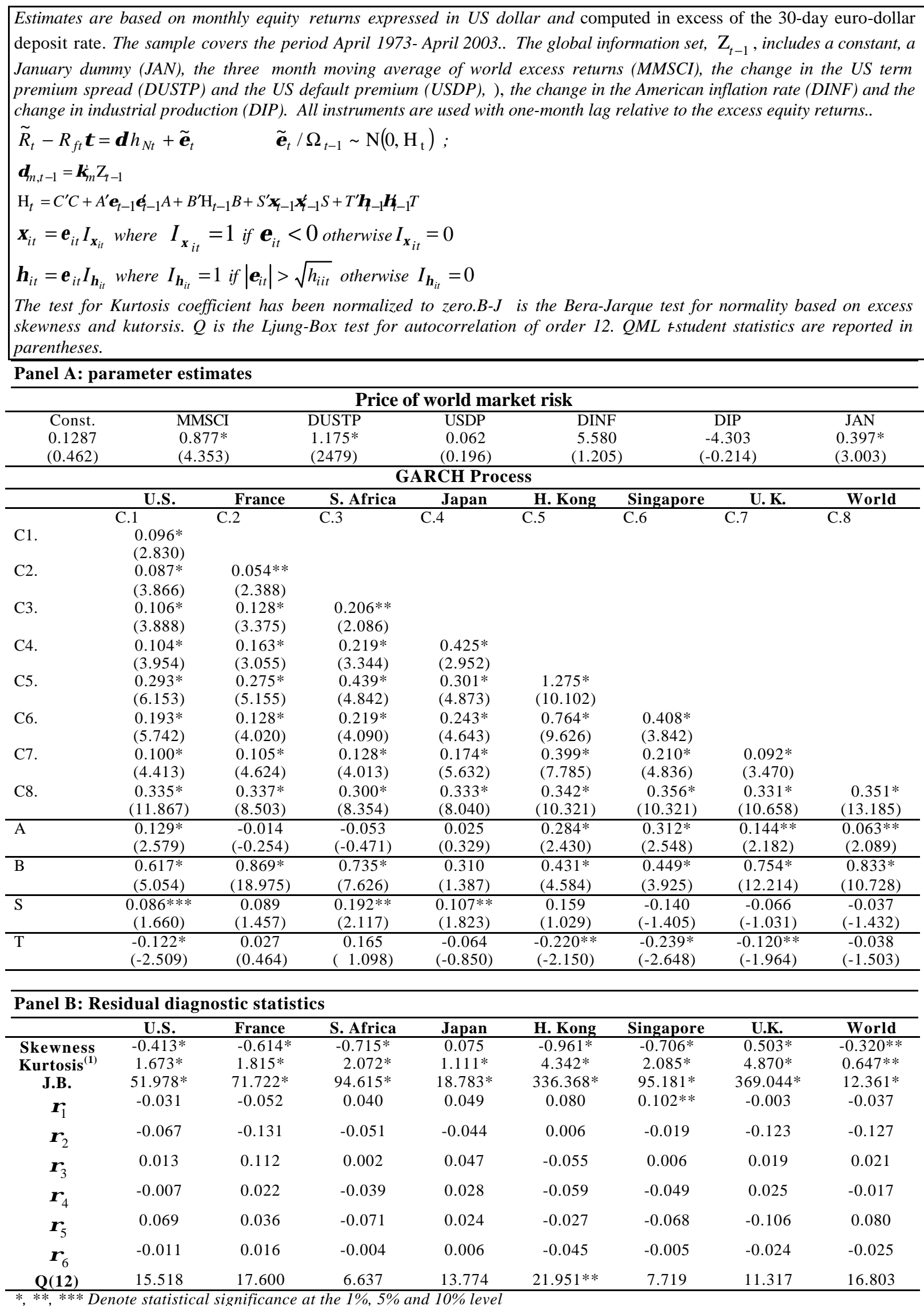




\section{Table IV : Specification Tests}

Estimates are based on monthly equity returns expressed in US dollar and computed in excess of the 30-day euro-dollar deposit rate. The sample covers the period April 1973-April 2003. The global information set, $\mathrm{Z}_{t-1}$, includes a constant, a January dummy (JAN), the three month moving average of world excess returns (MMSCI), the change in the US term premium spread (DUSTP) and the US default premium (USDP), the change in the American inflation rate (DINF) and the change in industrial production (DIP). All instruments are used with one-month lag relative to the excess equity returns.

$\tilde{R}_{t}-R_{f t} \tau=\delta h_{N t}+\tilde{\varepsilon}_{t} \quad \tilde{\varepsilon}_{t} / \Omega_{t-1} \sim \mathrm{N}\left(0, \mathrm{H}_{\mathrm{t}}\right) ;$

\section{$\underline{\text { Version } 1}$}

$\delta_{m, t-1}=\kappa_{m}^{\prime} \mathrm{Z}_{t-1}$

Version 2

$\tilde{R}_{t}-R_{f t} \tau=\alpha_{i}+\delta h_{N t}+\lambda_{i} h_{i i, t}+\tilde{\varepsilon}_{t} \quad \forall \quad i \quad \tilde{\varepsilon}_{t} / \Omega_{t-1} \sim \mathrm{N}\left(0, \mathrm{H}_{\mathrm{t}}\right)$

The covariance matrix is given by:

$\mathrm{H}_{t}=C^{\prime} C+A^{\prime} \varepsilon_{t-1} \varepsilon_{t-1}^{\prime} A+B^{\prime} \mathrm{H}_{t-1} B+S^{\prime} \xi_{t-1} \xi_{-1}^{\prime} S+T^{\prime} \eta_{-1} \eta_{-1}^{\prime} T$

$\xi_{i t}=\varepsilon_{i t} I_{\xi_{i t}}$ where $I_{\xi_{i t}}=1$ if $\varepsilon_{i t}<0$ otherwise $I_{\xi_{i t}}=0$

$\eta_{i t}=\varepsilon_{i t} I_{\eta_{i t}}$ where $I_{\eta_{i t}}=1$ if $\left|\varepsilon_{i t}\right|>\sqrt{h_{i i t}}$ otherwise $I_{\eta_{i t}}=0$

\begin{tabular}{|c|c|c|c|}
\hline Null Hypothesis & $\chi^{2}$ & $d f$ & p-value \\
\hline \multicolumn{4}{|c|}{ Version 1 } \\
\hline \multicolumn{4}{|c|}{ 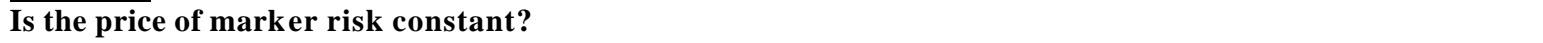 } \\
\hline$H_{0}: \quad \delta_{m, j}=0 \quad \forall j>1$ & 35.52 & 7 & 0.000 \\
\hline \multicolumn{4}{|l|}{ Version 2} \\
\hline \multicolumn{4}{|c|}{$\overline{\text { Are intercepts } \alpha_{i} \text { all equal to zero? }}$} \\
\hline$H_{0}: \quad \alpha_{i}=0 \quad \forall i$ & 7.605 & 8 & 0.472 \\
\hline \multicolumn{4}{|c|}{ Are the prices of specific risk equal to zero? } \\
\hline$H_{0}: \quad \lambda_{l}=0 \quad \forall i$ & 4.763 & 7 & 0.688 \\
\hline
\end{tabular}

Table V: Averages in percent for the annualised expected gains from international diversification

The table contains averages in percent for the annualised expected gains from international portfolio diversification computes from the QML estimates of the model. Gains are computed for each country as follows:

$\left.E\left(\tilde{R}_{P t}-\tilde{R}_{p t} / \Omega_{t-1}\right)=\delta_{t-1} \mid \psi_{t-1} \operatorname{Var}\left(\tilde{R}_{W t} / \Omega_{t-1}\right)-\operatorname{Cov}\left(\tilde{R}_{p t}, \tilde{R}_{W t} / \Omega_{t-1}\right)\right]$

\begin{tabular}{|c|c|c|c|c|}
\hline & 1973:04-1983:03 & 1983:04-1993:03 & 1993:04-2003:04 & 1973:03-2003:04 \\
\hline U.S. & $0.938^{*}$ & $1.817 *$ & $1.223^{*}$ & $1.311^{*}$ \\
\hline & $(3.059)$ & $(7.917)$ & $(7.716)$ & $(9.404)$ \\
\hline France & $2.863^{*}$ & $5.904 *$ & $2.985^{*}$ & $3.558 *$ \\
\hline & $(2.787)$ & $(9.258)$ & $(7.396)$ & $(8.628)$ \\
\hline S. Africa & $\begin{array}{c}3.828 * * \\
(2.193)\end{array}$ & $\begin{array}{l}11.148 * \\
(8.972)\end{array}$ & $\begin{array}{l}6.835^{*} \\
(6.462)\end{array}$ & $\begin{array}{l}7.321^{*} \\
(8.910)\end{array}$ \\
\hline Japan & $\begin{array}{l}1.984 * \\
(2.844)\end{array}$ & $\begin{array}{l}3.907 * \\
(9.425)\end{array}$ & $\begin{array}{l}4.203^{*} \\
(7.724)\end{array}$ & $\begin{array}{c}3.325^{*} \\
(10.391)\end{array}$ \\
\hline H. Kong & $\begin{array}{c}4.916 * * \\
(2.379)\end{array}$ & $\begin{array}{l}10.366^{*} \\
(6.557)\end{array}$ & $\begin{array}{l}7.514 * \\
(7.943)\end{array}$ & $\begin{array}{c}7.47 * \\
(8.056)\end{array}$ \\
\hline Singapore & $\begin{array}{c}3.414 * * * \\
(1.938)\end{array}$ & $\begin{array}{l}7.767 * \\
(7.824)\end{array}$ & $\begin{array}{l}5.307^{*} \\
(7.508)\end{array}$ & $\begin{array}{l}5.414^{*} \\
(7.512)\end{array}$ \\
\hline U.k. & $\begin{array}{l}1.128^{*} \\
(2.967)\end{array}$ & $\begin{array}{l}2.202^{*} \\
(8.872)\end{array}$ & $\begin{array}{l}2.914 * \\
(7.921)\end{array}$ & $\begin{array}{l}2.069^{*} \\
(8.427)\end{array}$ \\
\hline
\end{tabular}


Figure 1: The price of world market risk

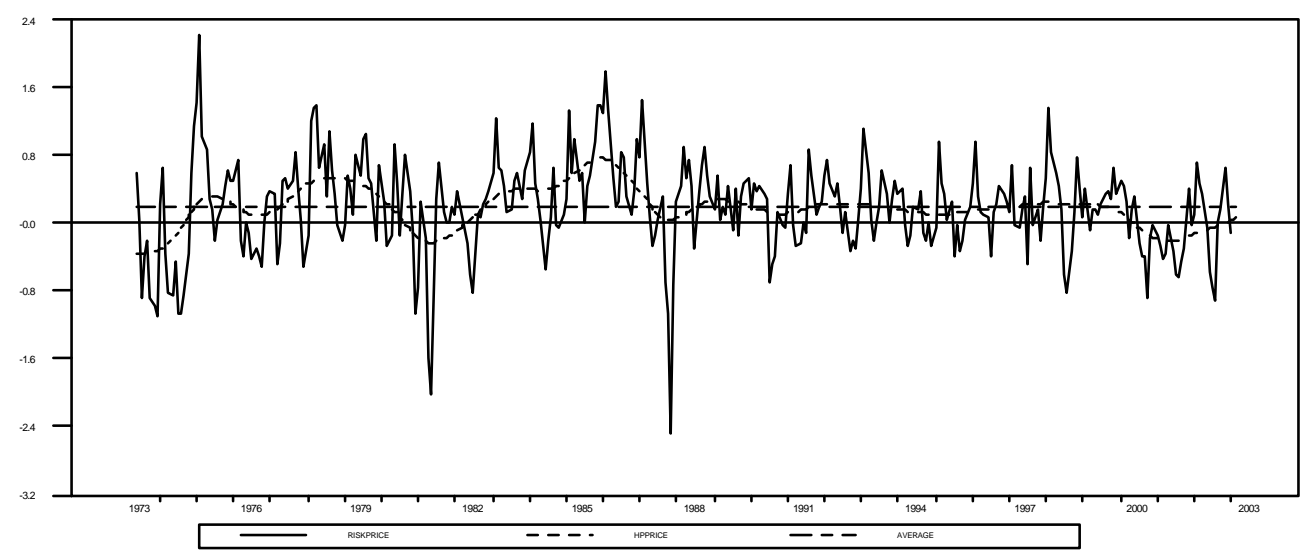

Figure 2 : The American market

2.1- Conditional correlation with market portfolio

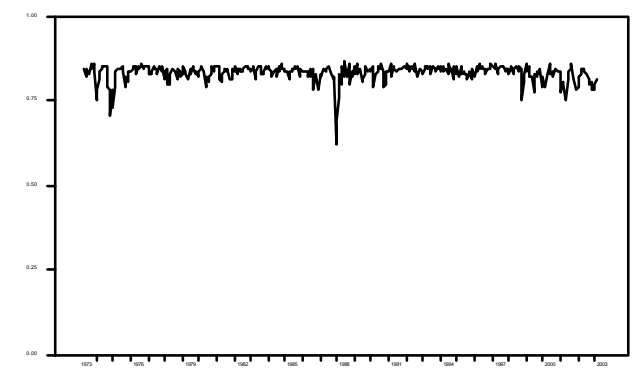

2.2- Expected gains from international diversification

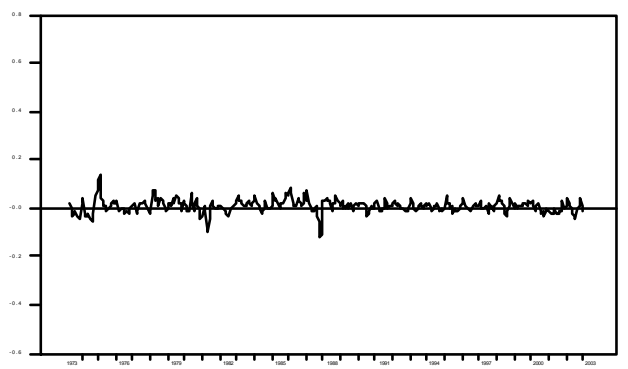

Figure 3: The French market

3.1- Conditional correlation with market portfolio

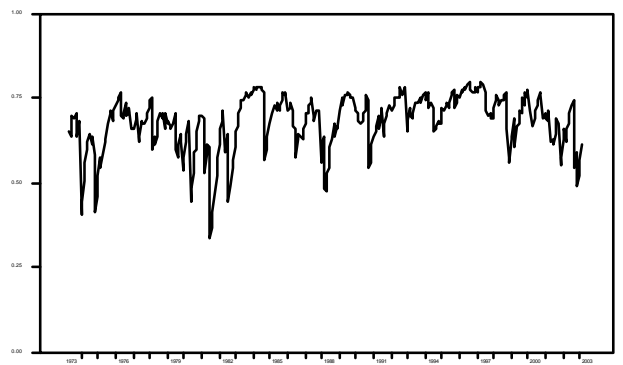

3.2- Expected gains from international diversification

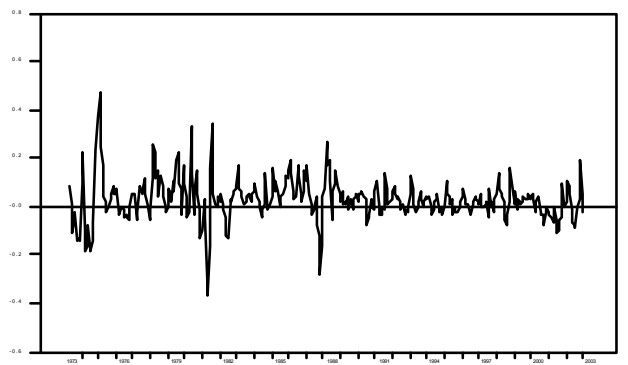

Figure 4: The Hong Kong market

4.1-Cconditional correlation with market portfolio

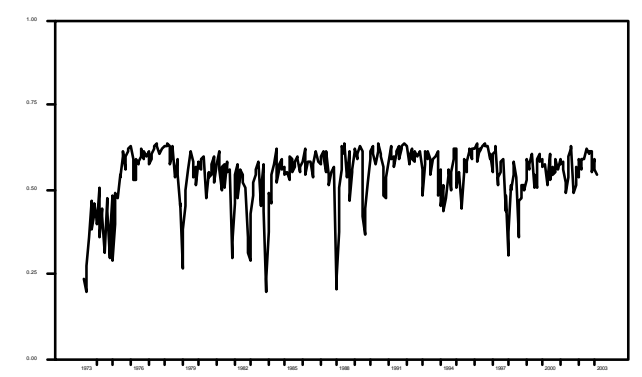

4.2- Expected gains from international diversification

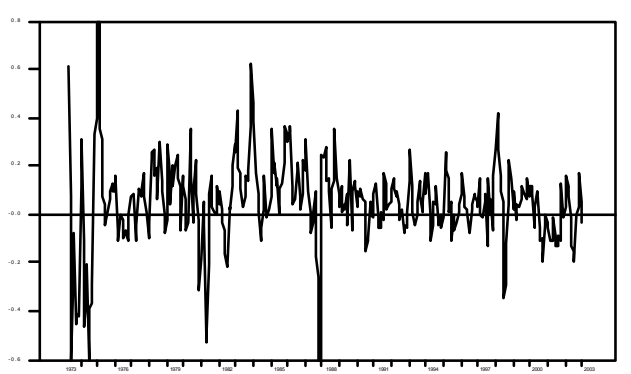


Figure 5: The Soutn-Africain market

5.1-Conditional correlation with market portfolio

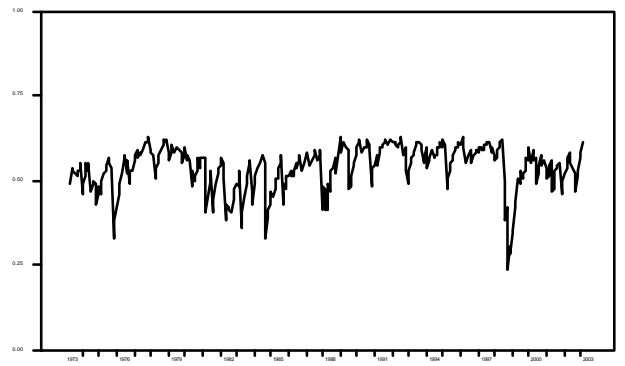

5.2- Expected gains from international diversification

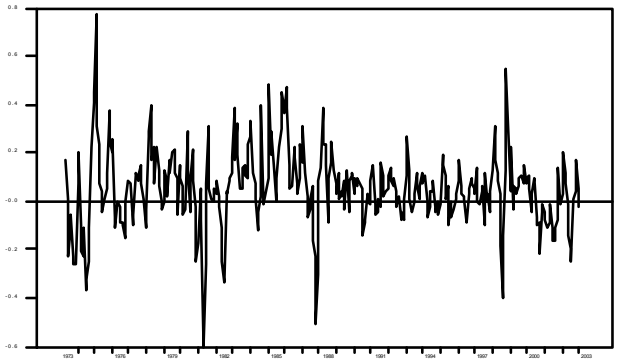

Figure 6: The Japanese market

6.1- Conditional correlation with market portfolio

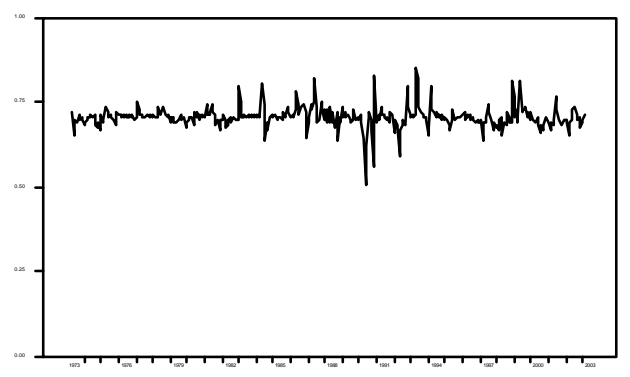

6.2- Expected gains from international diversification

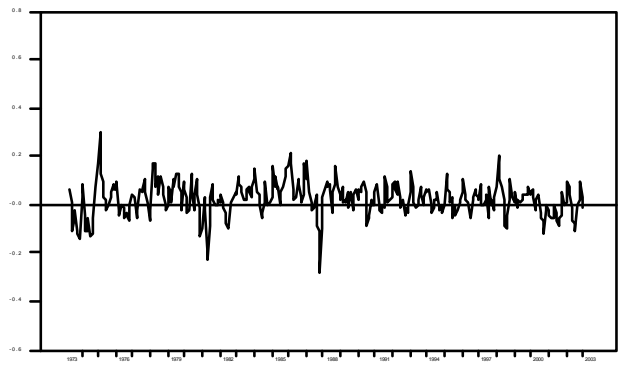

Figure 7 : The market of Singapore

7.1- Conditional correlation with market portfolio

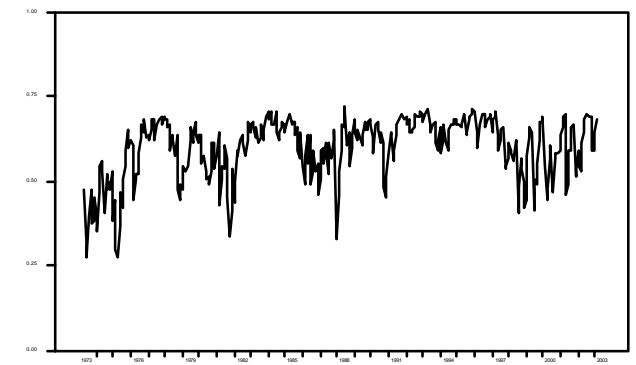

7.2- Expected gains from international diversification

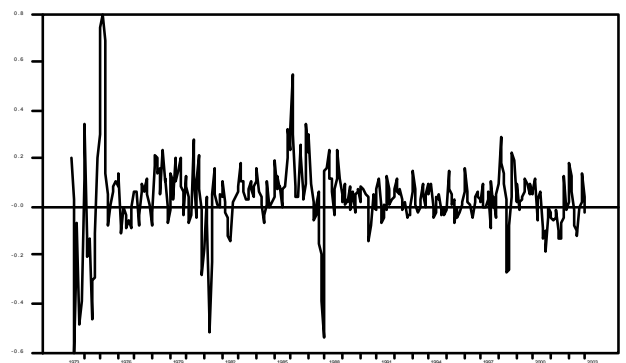

Figure 8: The British market

8.1-Cconditional correlation with market portfolio

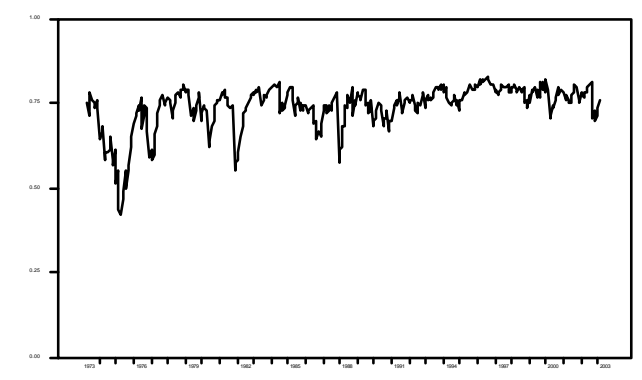

8.2- Expected gains from international diversification

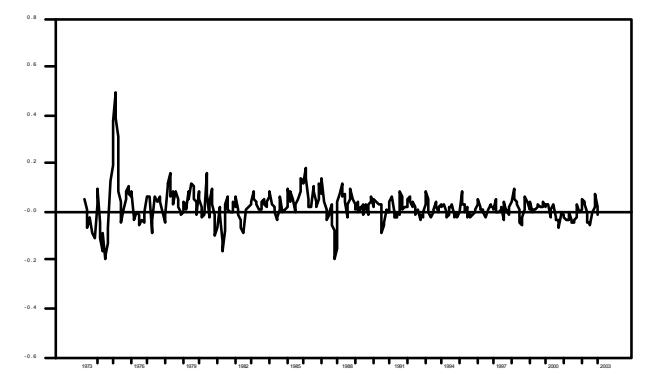

